\section{A Huge Neurofibroma of the Lower Back Invading the Spinal Cavity}

Han Moi Choi, Dongin Jo, Cheol Keun Kim, Hyun Gon Choi, Dong Hyeok Shin, Ki Il Uhm, Soon Heum Kim

Department of Plastic and Reconstructive Surgery, Konkuk University School of Medicine, Chungju, Korea

Correspondence: Soon Heum Kim

Department of Plastic and Reconstructive Surgery, Konkuk University School of Medicine 82 Gugwon-daero, Chungju 380-704, Korea

Tel: +82-10-5288-6505, Fax: +82-43-840-8962

E-mail: plastics7@gmail.com

No potential conflict of interest relevant to this article was reported.

Received: 7 May 2014 • Revised: 31 May 2014 • Accepted: 31 May 2014 pISSN: 2234-6163 • elSSN: 2234-6171

http://dx.doi.org/10.5999/aps.2015.42.3.373 • Arch Plast Surg 2015;42:373-375

Copyright (C) 2015 The Korean Society of Plastic and Reconstructive Surgeons This is an Open Access article distributed under the terms of the Creative Commons Attribution Non-Commercial License (http://creativecommons.org/licenses/by-nc/3.0/) which permits unrestricted non-commercial use, distribution, and reproduction in any medium, provided the original work is properly cited.

A 56-year-old woman came to the hospital with a rapidly growing mass on her lower back (Fig. 1). Thirty years earlier, she had been diagnosed with neurofibromatosis type 1 (Von Recklinghausen's disease). The patient had multiple nodules, which were scattered over her entire body from her late twenties. The mass was palpable two months before

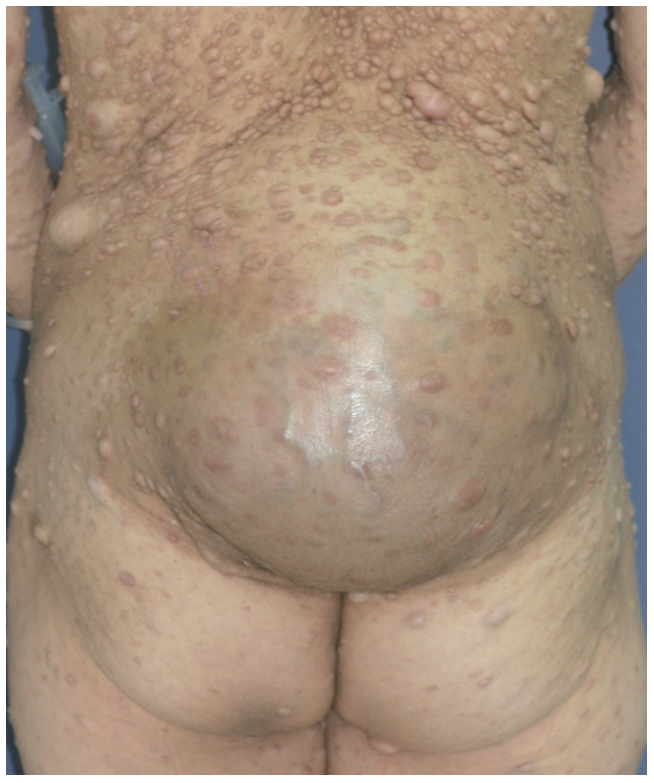

Fig. 1.

Photograph of a 56-year-old female neurofibromatosis type 1 patient. A mass measuring $30 \times 30 \mathrm{~cm}$ in size was found on the lower back. presentation to our department, and it had been growing rapidly for the final three weeks. When lying down, the patient's performance of physical activity was impaired due to the mass. An abdominal-pelvic multi-detector computed tomography scan and sonogram showed a huge mass with a fluid-filled central portion located at the lower back. Increased peripheral vascularity and malignant transformation of the neurofibroma were suspected. In addition, a spina bifida-like lesion was noted at the spinous process of the L4 spine (Fig. 2). However, neurologic symptoms were not observed. Because there appeared to be a direct connection between the mass and the spinal nerve, additional imaging was required to distinguish the origin of the mass. On magnetic resonance images, the mass had no direct connection with the spinal canal. The mass measured $30 \times 30 \mathrm{~cm}$ $\times 18 \mathrm{~cm}$ in size and gave the impression of an abscess or a malignant schwannoma. Before the operation, aspiration was performed in order to reduce the size and to increase the mobility of the mass; $350 \mathrm{~mL}$ of bloody discharge was drained and spindle cell nests and nuclear atypia were observed on the cytological examination. Spindle cells were formed by abnormal mitosis or cell division, leading to the development of a cancerous tumor. The patient underwent wide excision under general anesthesia. A vertical spindleshaped incision was made at the central portion of the mass. Dissection was performed between the skin flap and the peripheral muscle of the back. The skin was very thin but fast growing. Dissection was extended to the tendinous portion of the lower back muscle

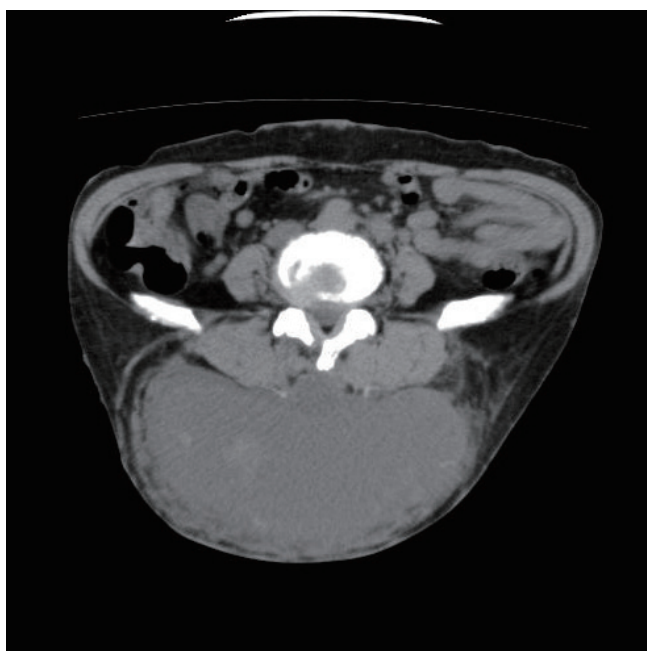

Fig. 2.

Axial view of the abdomen on enhanced computed tomography scan shows a spina bifida-like appearance on the lumbar spine and fluid collection at the central portion of the mass. 


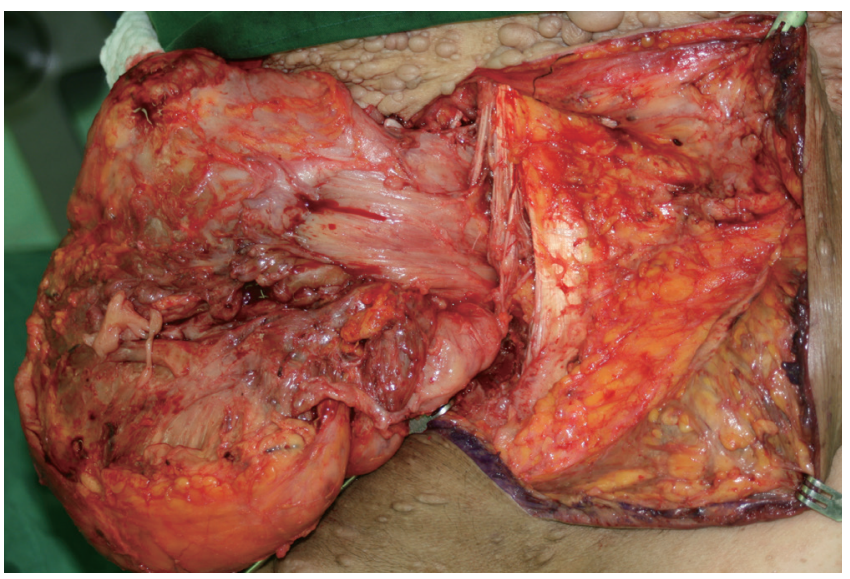

Fig. 3.

Photograph of the mass after dissection. The spinal cavity was perforated; however, no direct connection between the mass and the spinal nerve was observed.

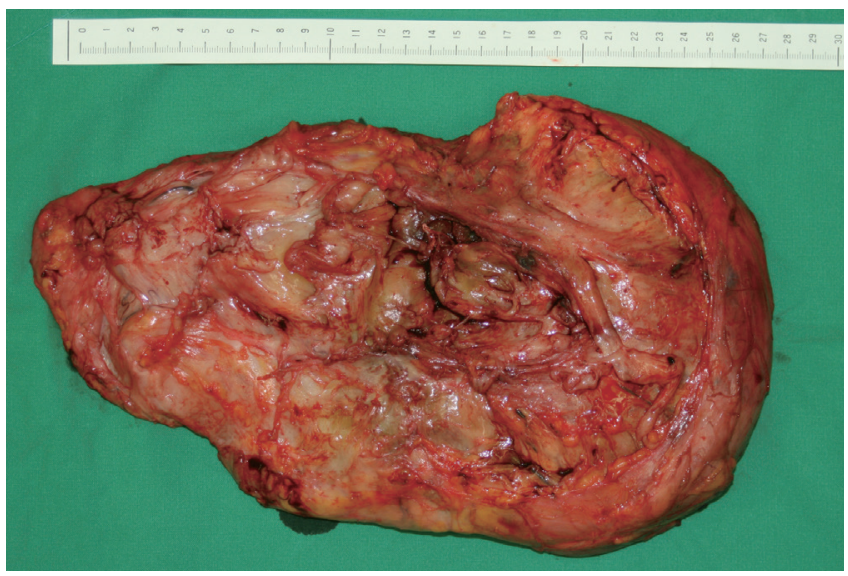

Fig. 4.

Photograph of an extracted mass after complete resection.

and spina bifida of the lumbar spine. On the base of the mass, dissection was performed between the lower back muscles and the mass. In the midsacral area, the mass was found to extend into the spinal cavity (Fig. 3); however, no direct connection with the spinal nerve was observed. After resection, the soft tissue defect was covered using a fasciocutaneous flap. The mass showed a well-encapsulated appearance with central necrosis. The mass was $28 \times$ $17 \times 7 \mathrm{~cm}$ in size and weighed approximately $4 \mathrm{~kg}$ (Fig. 4). The external wound margin was invaded by a neurofibromatic change. However, given that the back was already entirely invaded by neurofibromas, the wound margin necessarily contained some neurofibromas. After two weeks, the patient recovered completely without any complications (Fig. 5). The mass was confirmed to be a type 1 neurofibroma, and malignancy was not observed. The patient did not show any particular complaint for one year after the operation, and there has been no suspected sign of recurrence ever since. Neurofibroma is a benign tumor of the peripheral nervous system and could occur either accidently or in association with neurofibromatosis type 1 (NF type 1 ). NF type 1 shows a high-frequency malignant transformation on peripheral nerve sheath tumors [1]. Most of the neurofibromas invade the skin and the superficial subcutaneous tissue. However, on various occasions, the mass can be located near major nerves and blood vessels, even intracranially [2]. Complete excision of the neurofibroma is challenging because of its infiltrating nature and tendency of recurrence [3]. Previous studies have shown that patients with NF type 1 are at a much greater risk of cancer, particularly leukemia, glioma, and malignant peripheral nerve sheath tumor (MPNST) [4]. Accordingly, NF 1 patients should undergo a regular checkup. On an aspiration exam, spindle cells were found. Because spindle cells have a potential for transformation into malignant cells, complete surgical resection is essential. Spindle cells are often found in cancerous tumors such as cellular schwannoma, synovial sarcoma, MPNST, dermatofibrosarcoma protuberans, leiomyosarcoma, clear cell sarcoma, and melanoma 
[5]. We experienced a rare case of a huge neurofibroma suspected as a spina bifida on the lumbar level. As neurofibromas have a tendency toward malignant development, preoperative imaging is essential for distinguishing the character of the mass and the existence of metastasis. In addition, ongoing followup is critical for such cases.

\section{References}

1. Nielsen GP, Stemmer-Rachamimov AO, Ino Y, et al. Malignant transformation of neurofibromas in neurofibromatosis 1 is associated with $\mathrm{CDKN} 2 \mathrm{~A} / \mathrm{p} 16$ inactivation. Am J Pathol 1999;155:1879-84.

2. Ergun SS, Emel E, Karabekir S, et al. Extracranial diffuse neurofibroma with intracranial extension. Plast Reconstr Surg 2000;105:801-3.

3. Li WY, Reinisch JF. Cysts, pits, and tumors. Plast Reconstr Surg 2009;124:106e-116e.

4. Korf BR. Malignancy in neurofibromatosis type 1. Oncologist 2000;5:477-85.

5. Clemens MW, Murthy A, Przygodzki RM. Malignant peripheral nerve sheath tumor of the hand. Plast Reconstr Surg 2009;123:83e-85e.

\section{A Rare Case of Transitional Meningioma}

Joon Hyon Kim, Young Joon Kim, Hoon Kim, Sang Hyun Nam, Young Woong Choi

Department of Plastic and Reconstructive Surgery, Inje University Sanggye Paik Hospital, Inje University College of Medicine, Seoul, Korea

\section{Correspondence: Young Woong Choi}

Department of Plastic and Reconstructive Surgery, Inje University Sanggye Paik Hospital, Inje University College of Medicine, 1342 Dongil-ro, Nowon-gu, Seoul 139-707, Korea

Tel: +82-2-950-1048, Fax: +82-2-932-6373

E-mail:pshero2@naver.com

This article was presented as a poster at the 2 nd Research \& Reconstructive Forum on June 1-2, 2012 on the Gwangju, Korea.

No potential conflict of interest relevant to this article was reported.

Received: 27 Mar 2014 • Revised: 1 Jun 2014 • Accepted: 9 Jun 2014 pISSN: 2234-6163 • elSSN: 2234-6171

http://dx.doi.org/10.5999/aps.2015.42.3.375 • Arch Plast Surg 2015;42:375-377

Copyright (C) 2015 The Korean Society of Plastic and Reconstructive Surgeons

This is an Open Access article distributed under the terms of the Creative Commons Attribution Non-Commercial License (http://creativecommons.org/licenses/by-nc/3.0/) which permits unrestricted non-commercial use, distribution, and reproduction in any medium, provided the original work is properly cited.

Meningiomas are a diverse set of tumors arising from the meninges, which are the membranous layers surrounding the central nervous system. Most meningiomas grow inward toward the brain as discrete, well-defined, dural-based masses and are spherical or lobulated. The borders between the tumor and the brain are usually smooth and clear because they preserve the histologic structures, such as the tumor capsule, cerebrospinal fluid, arachnoid mater, and pia mater [1]. Considering such a growth pattern, we report a rare case of transitional meningioma misdiagnosed as a soft tissue tumor.

A 60-year-old female patient presented with a hard and fixed mass that grew spontaneously on her forehead within one year (Fig. 1). There was no history of trauma or exposure to carcinogens, and she was otherwise fit and well. Computed tomography (CT) showed frontal cortical thickening and swelling suggestive of a type of soft tissue tumor. To determine the character of the tumor-like mass, excision was performed (Fig. 2). The pathologist confirmed the mass as a transitional meningioma. Magnetic resonance imaging (MRI) which was taken after primary excision revealed an intracranial mass that was $3.0 \mathrm{~cm}$ in size, ovoid and well enhanced (Fig. 3). Wide-excision osteoplastic craniotomy via a bicoronal approach was performed under navigation guidance by neurosurgeon.

Transitional meningiomas are also called as mixed meningiomas, and these tumors have transitional between those of meningothelial and fibrous meningioma and they are common tumors with meningothelial, fibrous, psammomatous, and angioblastic meningiomas. $90 \%$ of meningiomas are consisting of those five types of meningiomas. The brain mass was also established as a meningothelialtype meningioma, $2.5 \times 2.3 \mathrm{~cm}$ in size. Histologically, the tumor was lobulated by intersecting collagenous fibers. Immunohistochemical staining was positive for vimentin and epithelial membrane antigen and

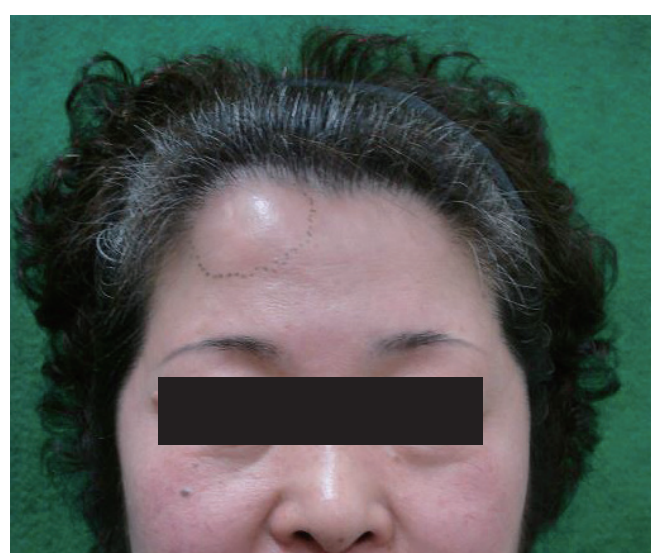

Fig. 1.

Preoperative photograph showing a lesion on the right forehead. 